\title{
Tetraphenylethene-Functionalized Polyethylene-based Polymers with Aggregation-Induced Emission
}

\begin{abstract}
Yu Jiang, Nikos Hadjichristidis*
Physical Sciences and Engineering Division, KAUST Catalysis Center, Polymer Synthesis Laboratory, King Abdullah University of Science and Technology (KAUST), Thuwal 23955, Saudi Arabia
\end{abstract}

ABSTRACT: A novel synthetic strategy toward a series of tetraphenylethene (TPE)functionalized polyethylene-based homo/copolymers is presented. Tris(3-(4-(1,2,2triphenylvinyl)phenoxy)propyl)borane, synthesized by hydroboration of (2-(4(allyloxy)phenyl)ethene-1,1,2-triyl)tribenzene with $\mathrm{BH}_{3}$, was used to initiate the polyhomologation of dimethylsulfoxonium methylide to afford well-defined TPE-terminated linear polyethylene $(\mathrm{PE})$. Combining this efficient strategy with ring-opening polymerization (ROP) or atom transfer radical copolymerization (ATRP) TPE-functionalized PE-based block copolymers have been synthesized. All synthesized polymers showed aggregation-induced emission (AIE)-behavior either in solution or in bulk. Self-assembly of the PE-based block copolymer in DMF resulted in strong emission due to the AIE effect of the aggregated TPE-PM core, the fluorescence intensity of the solution is directly related to the composition of block copolymers and the size of the micelle. The response of the AIE-operative fluorescence behavior toward the concentration of the block copolymer solutions has also been used to locate the CMC value of the block copolymers. The non-emissive dilute solutions of block copolymers became fluorescent when increasing concentrations above CMC. 


\section{INTRODUCTION}

Luminescent materials have attracted considerable attention in past decades due to their promising applications in electronic devices, chemosensors and biomedical areas. ${ }^{1-4}$ However, the conventional organic luminogens only emit high fluorescence in dilute solution while undergoing complete quenching in aggregation state. This aggregation-caused quenching (ACQ) effect limits their application in real-world. ${ }^{5}$ In 2001, Tang's group first reported one particular silole molecule which has exactly opposite phenomenon of ACQ emitting strongly in aggregation state. ${ }^{6}$ This interesting phenomenon was coined by Tang aggregation-induced emission (AIE). Since then, several organic AIE molecules have been developed and applied in bioimaging, OLED, chemosensing, stimuli-responsive system and so on. ${ }^{7-11}$ Depending on the development of AIE small molecules, AIE-active polymers have also been synthesized and investigated. The combination of polymers with the AIE small molecules have many advantages comparing to the small molecules, such as processability, good thermal stability and structural diversity. ${ }^{12-14}$ By introducing the AIE-gens into the polymer structures, the resulted AIE-active materials possess the polymer properties as well as the AIE characteristics and thus expand the application scope of AIE materials.

Recently, polymer micelle behavior ${ }^{15}$ has been a fascinating area and received considerable research attention, in particular of amphiphilic block copolymers, ${ }^{16}$ due to potential applications in drug delivery ${ }^{17}$ and catalysis. ${ }^{18}$ AIE-active amphiphilic block copolymers, which could selfassemble into micelles, have also been developed and applied in fluorescent probes area. ${ }^{19-21}$ For example, Zhu and co-works synthesized PNIPAM-based AIE fluorophores-contained block copolymers. These dual-responsive polymers self-assembled into reversible micelles with AIEactive turn-on fluorescence. Zhu's report provided a novel approach to interpret the influence of 
minor $\mathrm{pH}$ or temperature changes in cells. ${ }^{22}$ To our knowledge, AIE-active polyethylene-based block copolymers have never been reported. Since PE is a crystalline polymer, polyethylene-based block copolymers in general, since they can undergo crystallization-driven self-assembly (CDSA), is an interesting topic in recent years. ${ }^{23-26}$ Unique characteristics are added by crystallizable polymer micelles, such as strong solidification, "living growth" and complex structures. ${ }^{27-30}$ In the present work, we incorporate AIE-gens into polyethylene-based block copolymers to form AIEactive micelles, with the expectation to expand the potential applications of AIE materials.

Polyhomologation, recently developed by Shea et $a l^{31-34}$, is a powerful tool for the synthesis of well-defined linear polymethylene (equivalent to polyethylene, PE)-based materials. The mechanism involves the formation of an ate complex between a ylide (monomer) and an organoborane (initiator), followed by insertion of $-\mathrm{CH}_{2}-$ moiety into the three alkyl branches of borane with simultaneous release of dimethyl sulfoxide and regeneration of the alkyl borane species ready for the next cycle, affording a borane-link 3-arm star PE. A hydroxyl-terminated linear PE (PE-OH) is then obtained by oxidation/hydrolysis of the 3-arm star PE. A series of PEbased architectures are synthesized by combining this efficient $\mathrm{C} 1$ polymerization with other polymerizations. ${ }^{35-50}$ Herein, we wish to report the synthesis of AIE-active PE by using an AIE gens-contained initiator for polyhomologation. Different block copolymers were constructed by ATRP and ROP by using PE-based macroinitiators.

\section{EXPERIMENTAL SECTION}

Materials. 4-Hydroxybenzophenone (98\%), benzophenone (98\%), zinc powder, titanium tetrachloride $\left(\mathrm{TiCl}_{4}, \geq 98 \%\right.$ ), potassium carbonate (anhydrous, $\geq 99 \%$ ), allyl bromide $(99 \%)$, copper(I) bromide ( $\mathrm{CuBr}, 99.999 \%)$, borane dimethylsulfide complex solution (1.0 M in THF), 
${ }^{t} \mathrm{Bu}-\mathrm{P}_{2}$ (2.0 M in THF), $\alpha$-bromoisobutyryl bromide (98\%), trimethylamine $N$-oxide dihydrate (TAO $2 \mathrm{H}_{2} \mathrm{O}, \geq 99 \%$ ) were purchased from Aldrich and used as received. Pentamethyldiethylenetriamine (PMDETA, 99\%, Aldrich), $\varepsilon$-caprolactone (CL, $\geq 99 \%$ ), styrene ( $\geq 99 \%$ ), and tert-butyl acylate $(\geq 99 \%)$ were distilled over calcium hydride $\left(\mathrm{CaH}_{2}\right)$ before use. Tetrahydrofuran (THF) and toluene were refluxed over sodium/benzophenone and distilled under a nitrogen atmosphere just before use. Dimethylsulfoxonium methylide was prepared according to the Corey's method followed by switching the solvent from THF to toluene..$^{51-52}$

Measurements. The high-temperature gel permeation chromatography (HT-GPC) measurements were carried out with the Agilent PL-GPC 220 instrument equipped with one Plgel $10 \mu \mathrm{m}$ MIXED-B column and a differential refractive index (DRI) detector. 1,2,4Trichlorobenzene (TCB) was used as eluent at a flow rate of $1.0 \mathrm{~mL} / \mathrm{min}$ at $150{ }^{\circ} \mathrm{C}$. The system was calibrated with PS standards. The ${ }^{1} \mathrm{H}$ and ${ }^{13} \mathrm{C}$ NMR spectra were recorded with a Bruker AVANCE III-400, 500 or 600 spectrometer. Transmittance measurements were performed on a Thermo Evolution $600 \mathrm{UV}$-Vis spectrophotometer in quartz cuvettes of $10 \mathrm{~mm}$ path length at a wavelength of $500 \mathrm{~nm}$ at room temperature. Photoluminescence spectra were recorded on a Thermo Lumina Fluorescence Spectrometer equipped with an external water circulator for the thermostatted cell holder. Dynamic light scattering (DLS) measurements were carried out with a Malvern Zetasizer Nano ZS equipped with a TurboCorr correlator. The light source was a $30 \mathrm{~mW}$ He-Ne laser emitting vertically polarized light of $632.8 \mathrm{~nm}$ wavelength.

Synthesis of (4-(allyloxy)phenyl)(phenyl)methanone (Scheme 1). To a solution of 4Hydroxybenzophenone $(8.0 \mathrm{~g}, 40 \mathrm{mmol})$ in dry acetone $(50 \mathrm{~mL})$, dry $\mathrm{K}_{2} \mathrm{CO}_{3}(14.0 \mathrm{~g}, 48 \mathrm{mmol})$ and allyl bromide (5.81 g, $48 \mathrm{mmol}$ ) were added, and the mixture was stirred overnight, then filtered, and the solid was washed with acetone. The combined filtrate was evaporated, and the 
solvent was removed to give the crude (4-(allyloxy)phenyl)(phenyl)methanone which was used without purification.

\section{Synthesis of (2-(4-(allyloxy)phenyl)ethene-1,1,2-triyl)tribenzene (TPE-alkene, Scheme 1).}

$\mathrm{Zn}$ powder (3.9 g, $60.0 \mathrm{mmol})$, benzophenone $(2.73 \mathrm{~g}, \quad 15.0 \mathrm{mmol})$ and (4(allyloxy)phenyl)(phenyl)methanone $(2.96 \mathrm{~g}, 15.0 \mathrm{mmol})$ were placed into a $250 \mathrm{~mL}$ two-necked flask equipped with a condenser. The flask was evacuated under vacuum and flushed with argon three times, followed by addition of anhydrous THF $(80 \mathrm{~mL})$. Then the mixture was cooled to -78 ${ }^{\circ} \mathrm{C}$ and $\mathrm{TiCl}_{4}(3.3 \mathrm{~mL}, 30.0 \mathrm{mmol})$ was added dropwise. The mixture was slowly warmed to room temperature, stirred for $30 \mathrm{~min}$, and then refluxed overnight. After cooling down to room temperature, the reaction was quenched by $10 \%$ aqueous $\mathrm{K}_{2} \mathrm{CO}_{3}$ solution, and after vigorous stirring for $5 \mathrm{~min}$, the dispersed insoluble material was removed by vacuum filtration using a Celite pad. The organic phase was separated and the aqueous layer was extracted three times with diethyl ether $(60 \mathrm{~mL} \times 3)$. The combined organic fractions was washed with brine and dried over $\mathrm{MgSO}_{4}$. The solvent was removed to give the (2-(4-(allyloxy)phenyl)ethene-1,1,2-triyl)tribenzene (TPEalkene).

Synthesis of tetraphenylethene-polyethylene (TPE-PE, Scheme 1). In a typical procedure for the synthesis of TPE-PE $41,0.1 \mathrm{~mL}(0.5 \mathrm{mmol})$ of a THF solution of $\mathrm{BH}_{3} \cdot \mathrm{Me}_{2} \mathrm{~S}(5.0 \mathrm{M})$ was added over $5 \mathrm{~min}$ to a toluene solution $(4.9 \mathrm{~mL}, 0.70 \mathrm{~g}, 1.8 \mathrm{mmol})$ of (2-(4-(allyloxy)phenyl)ethene1,1,2-triyl)tribenzene at $0{ }^{\circ} \mathrm{C}$. The reaction was allowed to reach room temperature over $2 \mathrm{~h}$. The final concentration of the initiator solution in toluene was $0.1 \mathrm{M}$.

$3.0 \mathrm{~mL}$ of the initiator solution $(0.1 \mathrm{M}, 0.30 \mathrm{mmol})$ was added to a dimethylsulfoxonium methylide solution $(110 \mathrm{~mL}, 0.8 \mathrm{M}, 88.0 \mathrm{mmol})$ at $65^{\circ} \mathrm{C}$. After consumption of methylide, $0.20 \mathrm{~g}$ of TAO was added to the solution. Then, the solution was stirred for $2 \mathrm{~h}$ at $90{ }^{\circ} \mathrm{C}$ and precipitated 
in methanol. The white solid was filtered, dried under vacuum and characterized by ${ }^{1} \mathrm{H}$ NMR and $\operatorname{GPC}\left(1.13 \mathrm{~g}, M_{\mathrm{n}, \mathrm{NMR}}=1.5 \times 10^{3}, \mathrm{Ð}=1.08\right)$.

Synthesis of block copolymer TPE-PE-b-PCL (Scheme 2). ${ }^{t} \mathrm{Bu}-\mathrm{P}_{2}(0.10 \mathrm{~mL}, 2 \mathrm{M}, 0.2 \mathrm{mmol})$ was added to the solution of TPE-PE97-OH $(0.12 \mathrm{~g}, 0.04 \mathrm{mmol})$ in toluene $(2.0 \mathrm{~mL})$, then caprolactone $(0.29 \mathrm{~g}, 2.5 \mathrm{mmol})$ was added to the mixture. The resulted solution was stirred in a preheated oil bath at $90{ }^{\circ} \mathrm{C}$ for $14 \mathrm{~h}$. Then the reaction was quenched by adding $\mathrm{CH}_{3} \mathrm{COOH} / \mathrm{MeOH}$ (10 vol\%) and cooled to room temperature. The mixture was precipitated in methanol. The white solid was filtered, dried under vacuum and characterized by ${ }^{1} \mathrm{H}$ NMR and GPC (TPE-PE $97-b$ $\left.\mathrm{PCL}_{23}, 0.21 \mathrm{~g}, M_{\mathrm{n}, \mathrm{NMR}}=5.7 \times 10^{3}, \mathrm{Ð}=1.21\right)$.

Synthesis of macroinitiator TPE-PE-Br (Scheme 2). In a typical procedure for the synthesis of TPE-PE $82-\mathrm{Br}, \mathrm{TPE}_{-\mathrm{PE}}(0.55 \mathrm{~g}, 0.20 \mathrm{mmol}$ of $\mathrm{OH})$ and toluene $(20 \mathrm{~mL})$ were placed into a 50 $\mathrm{mL}$ Schlenk flask and the mixture was kept under vigorous stirring at $90{ }^{\circ} \mathrm{C}$ under Ar. Pyridine (0.32 mL, $4.0 \mathrm{mmol})$ and 2-bromoisobutyryl bromide (0.92 g, $4.0 \mathrm{mmol})$ were added dropwise. After stirring for $12 \mathrm{~h}$, the reaction mixture was cooled to room temperature and poured into 300 $\mathrm{mL}$ of acidic methanol (containing $20 \mathrm{~mL}$ of $1 \mathrm{M}$ aqueous $\mathrm{HCl}$ ). The solid was filtered, washed successively with methanol $(2 \times 20 \mathrm{~mL}), 1 \mathrm{M}$ aqueous $\mathrm{HCl}(2 \times 10 \mathrm{~mL})$, and methanol $(2 \times 20 \mathrm{~mL})$, and dried at $50{ }^{\circ} \mathrm{C}$ for $3 \mathrm{~h}$ in vacuum to give an off-white solid (TPE-PE $82-\mathrm{Br}, 0.50 \mathrm{~g}, \mathrm{M}_{\mathrm{n}, \mathrm{NMR}}=$ $\left.2.8 \times 10^{3}, \mathrm{Ð}=1.07\right)$

Synthesis of block copolymer TPE-PE-b-PS (Scheme 2). Copper(I) bromide (CuBr, 7 mg, 0.05 $\mathrm{mmol})$, TPE-PE41-Br $(50 \mathrm{mg}, 0.03 \mathrm{mmol})$, styrene $(0.69 \mathrm{~g}, 6.6 \mathrm{mmol})$ and toluene $(4 \mathrm{~mL})$ was placed into a $25 \mathrm{~mL}$ Schlenk flask. The mixture was degassed by three freeze-pump-thaw (FTP) cycles and then pentamethyldiethylenetriamine (PMDETA, $17 \mathrm{mg}, 0.10 \mathrm{mmol}$ ) was added and then the mixture was subjected to another freeze-pump-thaw cycle. The solution was immediately 
immersed into an oil bath set at $100{ }^{\circ} \mathrm{C}$ to start the polymerization under stirring. After $24 \mathrm{~h}$, the polymerization was stopped by cooling in a liquid nitrogen bath. The cloudy solution was heated to clear and poured into cold methanol $(100 \mathrm{~mL})$ with stirring. The white solid was filtered, dried under vacuum and characterized by ${ }^{1} \mathrm{H}$ NMR and GPC $\left(\right.$ TPE-PE $41-b-P_{38}, 150 \mathrm{mg}, M_{\mathrm{n}, \mathrm{NMR}}=$ $\left.5.6 \times 10^{3}, Ð=1.10\right)$

Synthesis of block copolymer TPE-PE-b-PtBA (Scheme 2). In a typical procedure for the synthesis of TPE-PE $82-b-\mathrm{P} t \mathrm{BA}_{29}$, copper(I) bromide $(\mathrm{CuBr}, 7 \mathrm{mg}, 0.05 \mathrm{mmol})$, TPE-PE $82-\mathrm{Br}(80$ $\mathrm{mg}, 0.03 \mathrm{mmol})$, tert-butyl acrylate $(1.69 \mathrm{~g}, 13.2 \mathrm{mmol})$ and toluene $(4 \mathrm{~mL})$ was placed into a 25 mL Schlenk flask.. The mixture was degassed by three freeze-pump-thaw (FTP) cycles and then pentamethyldiethylenetriamine (PMDETA, $17 \mathrm{mg}, 0.10 \mathrm{mmol}$ ) was added and then the mixture was subjected to another freeze-pump-thaw cycle. The solution was immediately immersed into an oil bath set at $100{ }^{\circ} \mathrm{C}$ to start the polymerization under stirring. After $24 \mathrm{~h}$, the polymerization was stopped by cooling in a liquid nitrogen bath. The cloudy solution was heated to clear and poured into cold methanol $(100 \mathrm{~mL})$ with stirring. The white solid was filtered, dried under vacuum and characterized by ${ }^{1} \mathrm{H}$ NMR and GPC (TPE-PE $\left.82-b-\mathrm{P} t \mathrm{BA}_{29}, 170 \mathrm{mg}, M_{\mathrm{n}, \mathrm{NMR}}=6.5 \times 10^{3}, \mathrm{Ð}=1.23\right)$

\section{Scheme 1. Synthesis of tetraphenylethylene-terminated polyethylene (TPE-PE)}

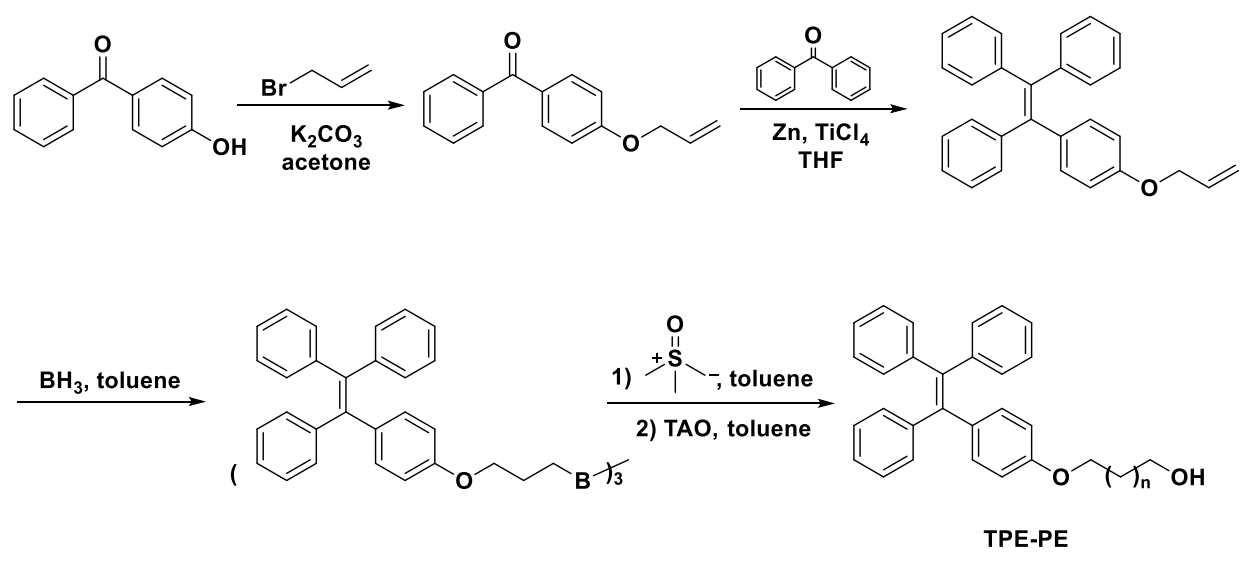




\section{RESULTS AND DISCUSSION}

Synthesis and Characterization of PE-based AIE Polymers. As illustrated in Scheme 1, (2(4(allyloxy)phenyl)(phenyl)methanone was synthesized from 4-hydroxybenzophenone in the first step, followed by the McMurry coupling reaction to afford the alkene-functionalized tetraphenylethyene (TPE-alkene). The chemical structure of TPE-alkene was confirmed by ${ }^{1} \mathrm{H}$ NMR and ${ }^{13} \mathrm{C}$ NMR (Figure S1). TPE-alkene was reacted with $\mathrm{BH}_{3}$ to afford the initiator of the subsequent polyhomologation (Scheme 1). A series of well-defined TPE-terminated polyethylenes (TPE-PEs) with different molecular weight were synthesized. The molecular characteristics of TPE-PEs are given in Table 1 . The molecular weight was determined by ${ }^{1} \mathrm{H}$ NMR end-group analysis and calculated according to the formula (Table 1). The polydispersity index ( $=M_{\mathrm{w}} / M_{\mathrm{n}}$ ) was determined by high-temperature gel permeation chromatography (HT-GPC) with polystyrene standards $(\mathrm{\Xi}=1.07-1.14)$. All GPC traces are monomodal with narrow molecular weight distributions (Figure 1). All polymers were characterized by ${ }^{1} \mathrm{H}$ NMR, as an example the ${ }^{1} \mathrm{H}$ NMR spectrum of polymer TPE-PE 41 is shown in Figure $2 \mathrm{~b}$. Comparison to that of the corresponding TPE-alkene (Figure 2a), reveals that the resonance signals (a), (b) and (c) belonging to allyl group disappeared and new signal (f') between 1.20-1.40 ppm belonging to the PE chain appeared, thus proving the success of polymerization. The signals (d') at $\delta 6.70,6.95$ and $7.15 \mathrm{ppm}$ with an integration ratio of 15:2:2, assigned to protons of TPE, indicate that the TPE group remained intact during the polyhomologation. 


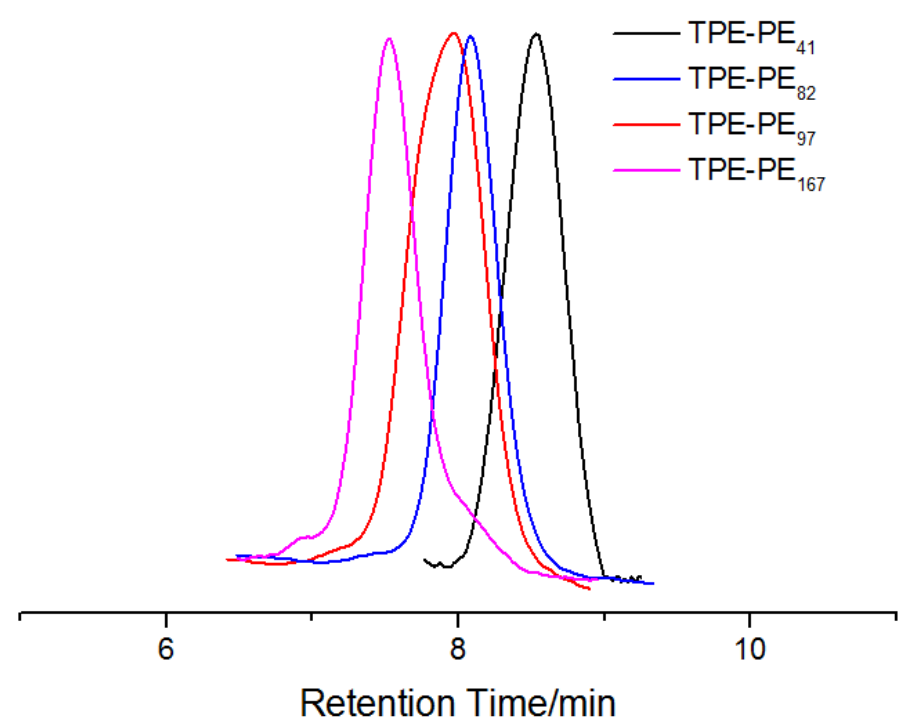

Figure 1. HT-GPC (TCB at $\left.150^{\circ} \mathrm{C}\right)$ traces of TPE-PEs.

Table 1. Molecular characteristics of TPE active PE-based polymers

\begin{tabular}{|c|c|c|c|c|c|c|}
\hline \multirow{2}{*}{ Entry } & \multirow{2}{*}{ Sample } & \multirow{2}{*}{$M_{\mathrm{n}, \mathrm{NMR}}^{\mathrm{a}}$} & \multirow{2}{*}{$M_{\mathrm{n}, \mathrm{GPC}}^{\mathrm{b}}$} & \multicolumn{2}{|c|}{$\mathrm{DP}^{\mathrm{a}}$} & \multirow{2}{*}{$\oplus^{b}$} \\
\hline & & & & $\mathrm{PE}$ & coblock & \\
\hline 1 & TPE-PE 41 & 1500 & 3500 & 41 & - & 1.08 \\
\hline 2 & TPE-PE 82 & 2700 & 6300 & 82 & - & 1.07 \\
\hline 3 & TPE-PE 97 & 3100 & 7700 & 97 & - & 1.14 \\
\hline 4 & TPE-PE 167 & 5100 & 12100 & 167 & - & 1.10 \\
\hline 5 & 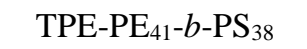 & 5600 & 12900 & 41 & 38 & 1.10 \\
\hline 6 & $\mathrm{TPE} \mathrm{PE}_{97}-b-\mathrm{PCL}_{23}$ & 5700 & 9000 & 97 & 23 & 1.21 \\
\hline 7 & $\mathrm{TPE}^{\mathrm{P}} \mathrm{E}_{82}-b-\mathrm{P} t \mathrm{BA}_{29}$ & 6500 & 9500 & 82 & 29 & 1.23 \\
\hline 8 & $\mathrm{TPE} \mathrm{PE}_{82}-b-\mathrm{P} t \mathrm{BA}_{80}$ & 13000 & 21400 & 82 & 80 & 1.32 \\
\hline 9 & $\mathrm{TPE}_{-\mathrm{PE}}{ }_{82}-b-\mathrm{P} t \mathrm{BA}_{150}$ & 22000 & 41800 & 82 & 150 & 1.37 \\
\hline
\end{tabular}

${ }^{\mathrm{a}} M_{\mathrm{n}, \mathrm{NMR}}$ and DP were calculated from ${ }^{1} \mathrm{H}$ NMR spectra $\left(600 \mathrm{MHz}, \mathrm{C}_{2} \mathrm{D}_{2} \mathrm{Cl}_{4}, 90{ }^{\circ} \mathrm{C}\right)$; ${ }^{\mathrm{b}} \mathrm{Ð}\left(M_{\mathrm{w}} / M_{\mathrm{n}}\right)$ and $M_{\mathrm{n}, \mathrm{GPC}}$, determined by HT-GPC $\left(1,2,4\right.$-trichlorobenzene, $150^{\circ} \mathrm{C}$, PS standards $) . M_{\mathrm{n}, \mathrm{NMR}}$, TPE-PE $=\left(\mathrm{DP}_{\mathrm{PE}}+1\right) \times 28+\mathrm{MW}_{\mathrm{TPE}}+$ $\mathrm{MW} \mathrm{OH}_{\mathrm{n}, \mathrm{NMR}}$, coblock polymer $=\left(\mathrm{DP}_{\text {coblock }}\right) \times \mathrm{MW}_{\text {monomer of coblock }}+M_{\mathrm{n}, \mathrm{NMR}}$, TPE-PE. 


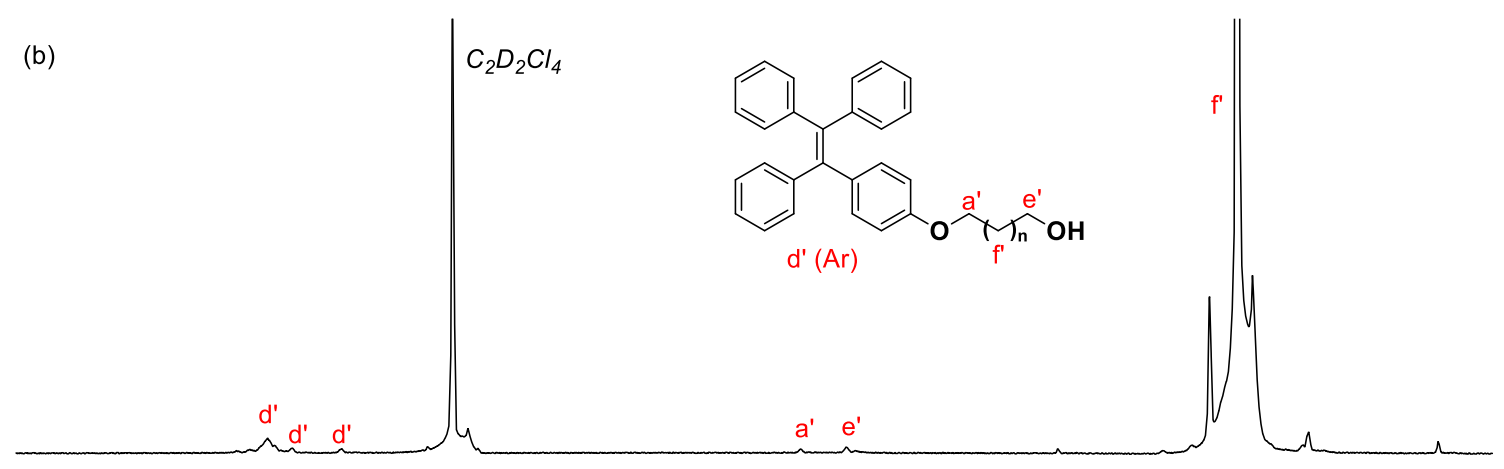

(a)

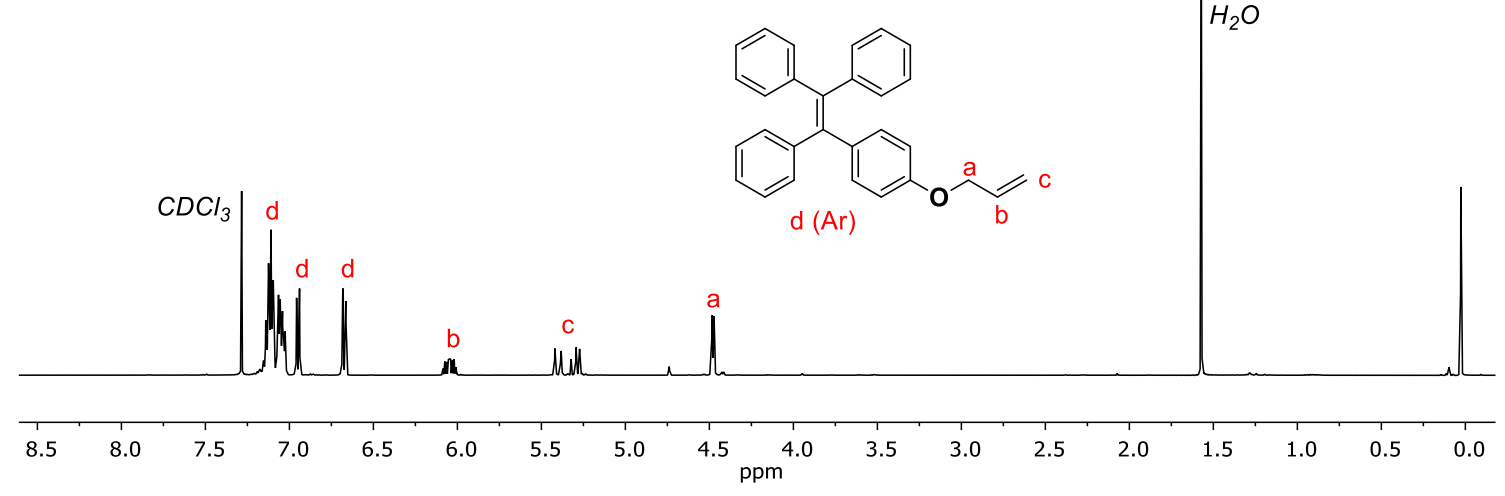

Figure 2. ${ }^{1} \mathrm{H}$ NMR spectra of the: (a) TPE-alkene $\left(\mathrm{CDCl}_{3}, 25{ }^{\circ} \mathrm{C}, 500 \mathrm{MHz}\right)$; (b) TPE-PE 41 $\left(\mathrm{C}_{2} \mathrm{D}_{2} \mathrm{Cl}_{4}, 90^{\circ} \mathrm{C}, 600 \mathrm{MHz}\right)$.

With the successful results on TPE-PE synthesis in hand, a series of TPE-PE-based block copolymers were synthesized (Scheme 2). The hydroxyl group of TPE-PE was utilized to initiate the ROP of $\varepsilon$-caprolactone with the phosphazene superbase ${ }^{t} \mathrm{Bu}-\mathrm{P}_{2}$ as the catalyst in toluene at $80{ }^{\circ} \mathrm{C}$ to form TPE-PE- $b$-PCL. The hydroxyl group of TPE-PE was also modified with 2 bromoisobutyryl bromide to give the ATRP macroinitiator TPE-PE-Br. Then TPE-PE-Br was employed to initiate the ATRP polymerization of styrene or tert-butyl acrylate affording the corresponding block copolymers TPE-PE- $b$-PS or TPE-PE- $b$-P $t$ BA. The molecular characteristics and HT-GPC traces of block copolymers are shown in Table 1, Figure 3, Figure S2 and S3 (ESI†े). Three block copolymers TPE-PE $82-b-\mathrm{P}_{t} \mathrm{BA}_{\mathrm{x}}$ with different DP (x) of tert-butyl acrylate, were synthesized from the same macroinitiator TPE-PE82-Br (Table 1, line 7-9). As shown in Figure 3 
all block copolymers TPE-PE82- $b-\mathrm{P} t \mathrm{BA}_{\mathrm{x}}$ are eluted earlier (higher molecular weight) than the corresponding precursor TPE-PE82. Similar results are observed from HT-GPC traces of the other block copolymers (Figure S2 and S3, ESI $\dagger$ ). As shown in the ${ }^{1} \mathrm{H}$ NMR spectra, both signals due to PCL, PS and PtBA blocks as well as TPE group can be identified (Figure 4).

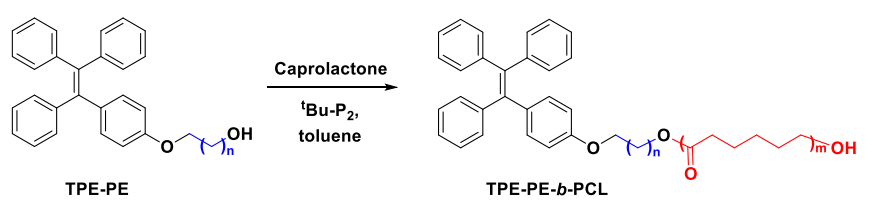

(b)

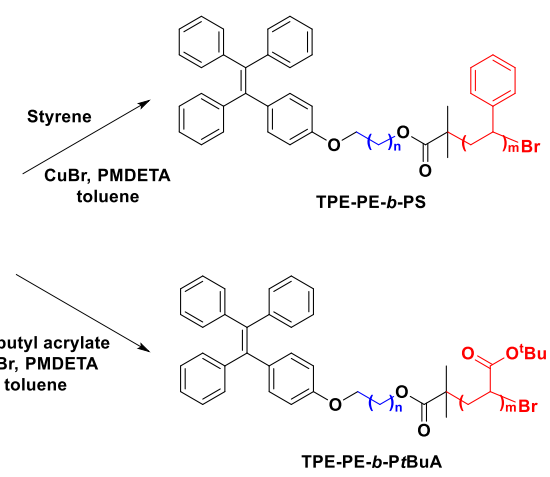

Scheme 2. Synthesis of TPE-terminated block copolymers

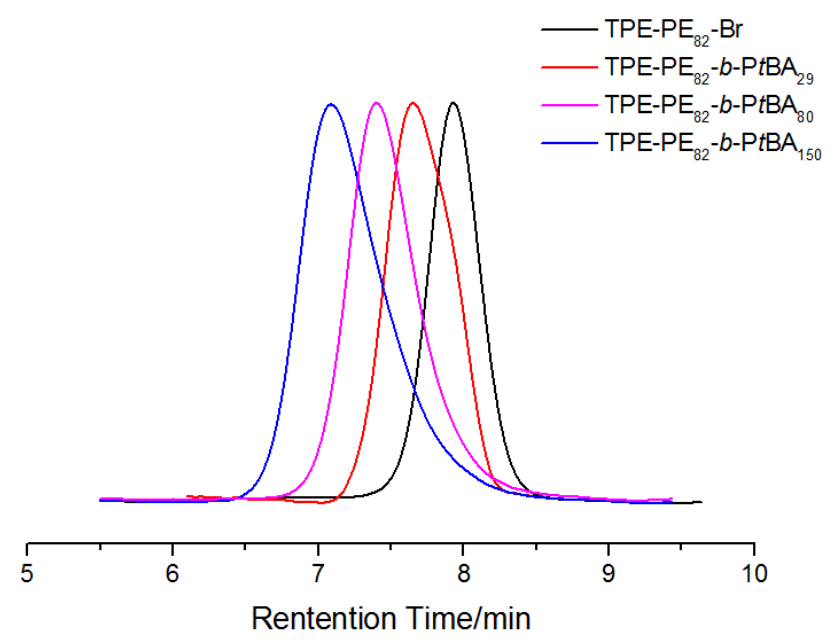

Figure 3. HT-GPC $\left(\mathrm{TCB}\right.$ at $\left.150{ }^{\circ} \mathrm{C}\right)$ traces of TPE-PE- $b$-P $t$ BAs. 


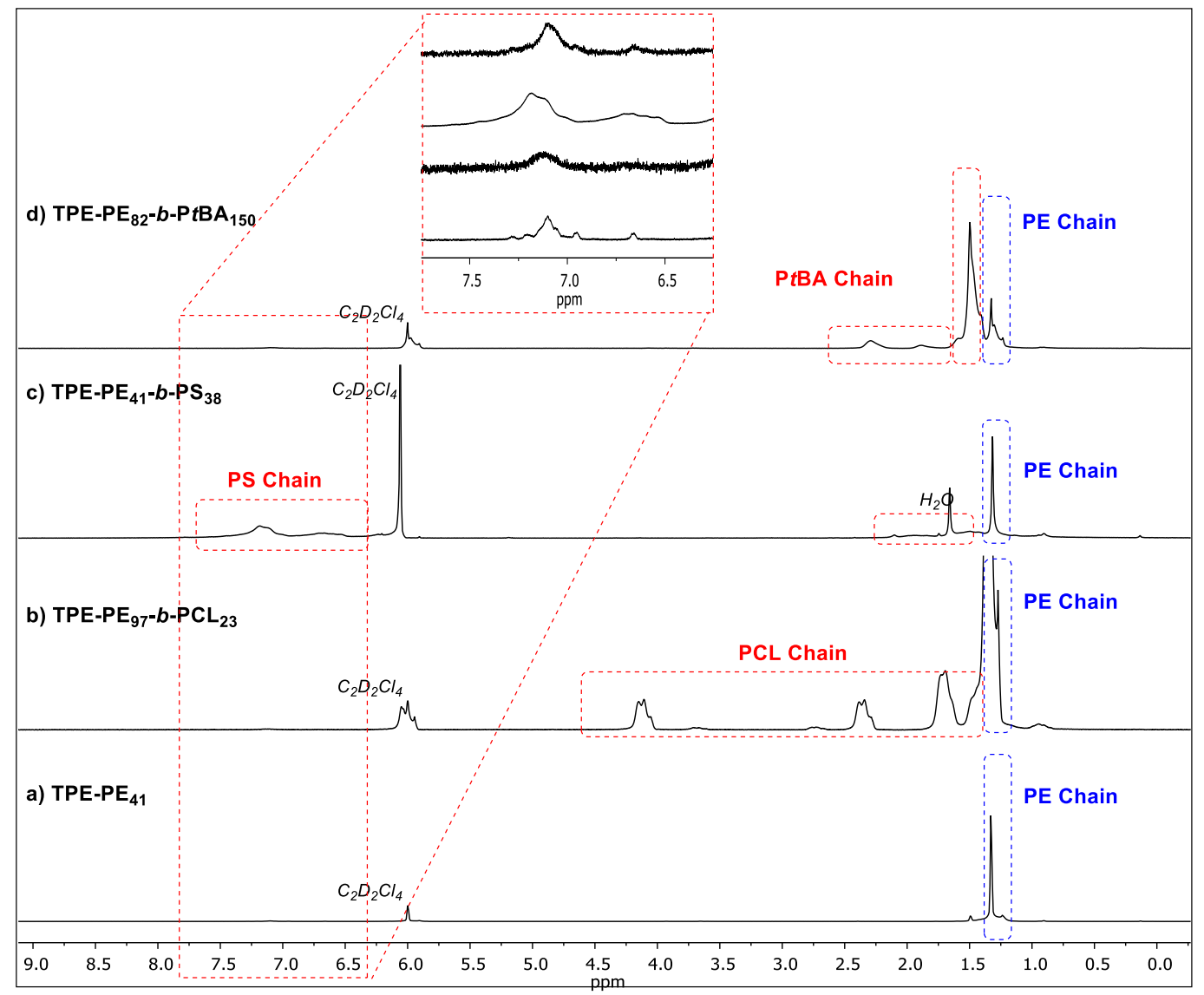

Figure 4. ${ }^{1} \mathrm{H}$ NMR (600 MHz) spectra of the : (a) TPE-PE 41 ; (b) TPE-PE $97-b-\mathrm{PCL}_{23}$; (c) TPE$\mathrm{PE}_{41}-b-\mathrm{PS}_{38}$; (d) TPE-PE $82-b-\mathrm{P} \mathrm{BA}_{150}$ in $\mathrm{C}_{2} \mathrm{D}_{2} \mathrm{Cl}_{4}$ at $90{ }^{\circ} \mathrm{C}$.

Aggregation-Induced Emission. The emission characteristics of the solutions of TPE-PE-based polymers were then investigated. The AIE behavior of TPE-PE 82 was investigated in toluene/nhexane mixture at a concentration of $0.1 \mathrm{~g} / \mathrm{L}$. As shown in Figure $5 \mathrm{a}$ and Figure $\mathrm{S} 5$, the addition of $n$-hexane into the toluene solution induced the molecular aggregation and gradually enhanced its photoluminescence (PL) intensities. At 90 vol \% $n$-hexane fraction, the highest intensity was observed (4.5-fold compared to that of pure toluene solution) (Figure S5, ESI $\dagger$ ). For the block copolymers, $\mathrm{THF} / \mathrm{H}_{2} \mathrm{O}$ were selected as solvent and similar results were observed, whereas addition of non-solvent $\left(\mathrm{H}_{2} \mathrm{O}\right)$ to good solvent (THF) also resulted in a rapid increase of the 
emission (Figure 5b-d and S4, ESI†). The PL intensities of TPE-PE $82-b-\mathrm{P} t \mathrm{BA}_{\mathrm{x}}$ are summarized in Figure 5c. The lower TPE content in TPE-PE $82-b-\mathrm{P}_{\mathrm{B}} \mathrm{BA}_{80}$ and TPE-PE $82-b-\mathrm{P}_{t} \mathrm{BA}_{150}$ resulted in the lower PL intensity in comparison to TPE-PE $82-b-\mathrm{P} \mathrm{BA}_{29}$ solution. Solutions of TPE-PE82- $b-$ $\mathrm{P} \mathrm{BA}_{29}$ with low $\mathrm{H}_{2} \mathrm{O}$ fraction ( $<60$ vol \%) have low PL intensity which increases abruptly to reach its highest value for the $90 \mathrm{vol} \%-\mathrm{H}_{2} \mathrm{O}$ solution, which is about 12 -fold compared with that in pure THF, because of the strong aggregation (Figure $5 \mathrm{~b}$ and $5 \mathrm{~d}$ ). The aggregation was also confirmed by the decreasing transmittance of the solutions. As shown in Figure 5d, the transmittance of the TPE-PE $82-b-\mathrm{P} \mathrm{BA}_{29}$ solutions decreases when the amount of $\mathrm{H}_{2} \mathrm{O}$ increases, along with the increase of PL intensity as the macromolecular aggregate. DLS was used to check the nanoparticle size in the TPE-PE $82-b-\mathrm{P}_{t} \mathrm{BA}_{29}$ solutions (Figure $\mathrm{S} 7$ ). Clearly, the average hydrodynamic diameter $\left(D_{\mathrm{h}}\right)$ of the nanoparticles increased with the $\mathrm{H}_{2} \mathrm{O}$ fraction. $D_{\mathrm{h}}$ value was $360 \mathrm{~nm}$ in $30 \mathrm{vol} \%$ of $\mathrm{H}_{2} \mathrm{O}, 684 \mathrm{~nm}$ in $70 \mathrm{vol} \%$ of $\mathrm{H}_{2} \mathrm{O}$, and $841 \mathrm{~nm}$ in $90 \mathrm{vol} \%$ of $\mathrm{H}_{2} \mathrm{O}$, along with the increase of PL intensity as the macromolecular aggregate. 

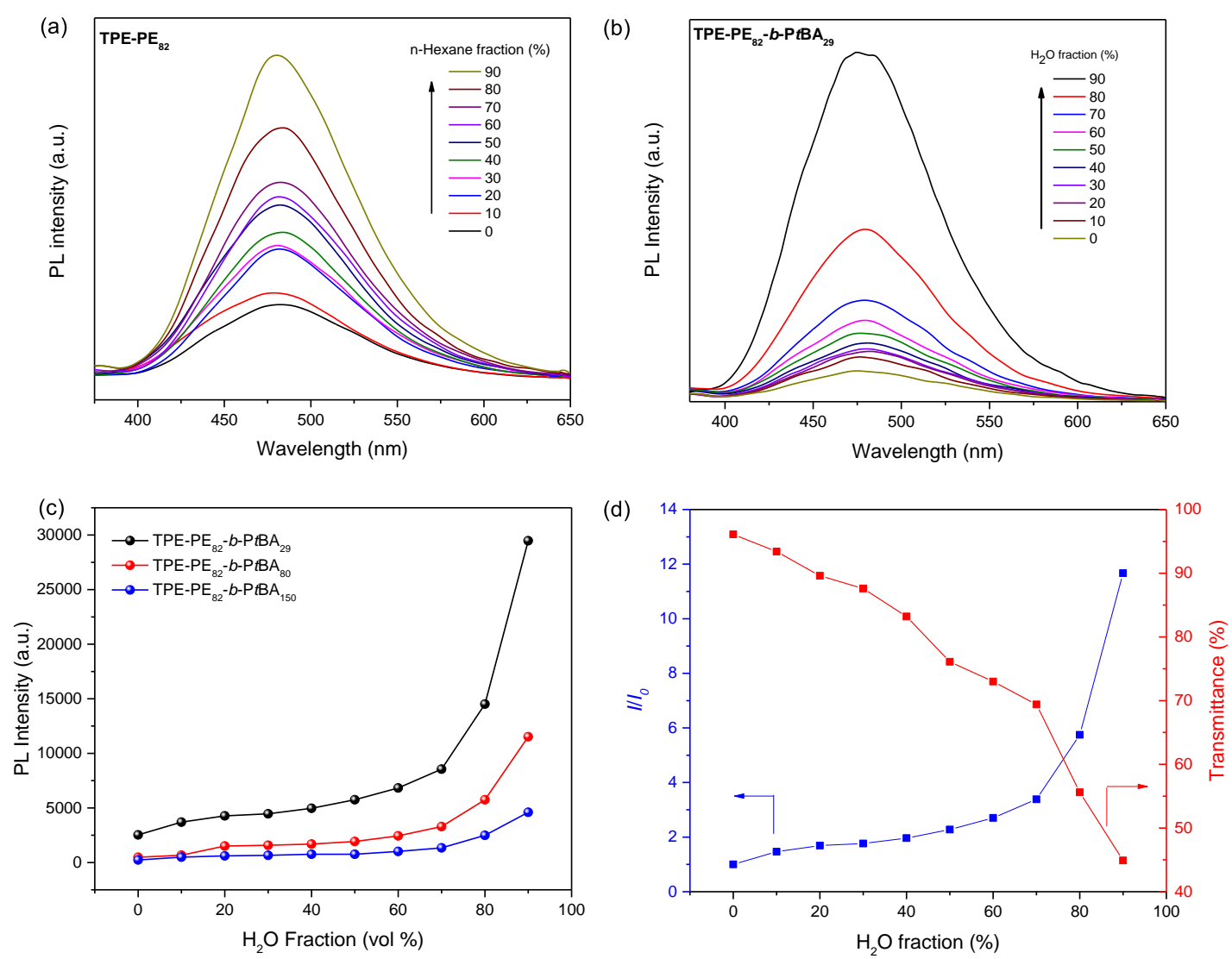

Figure 5. (a) Photoluminescence (PL) spectra of TPE-PE 82 in toluene/ $n$-hexane mixtures with different $n$-hexane fractions at a concentration of $0.1 \mathrm{~g} / \mathrm{L}$; (b) PL spectra of TPE-PE $82-b-\mathrm{P} \mathrm{BA}_{29}$ in $\mathrm{THF} / \mathrm{H}_{2} \mathrm{O}$ mixtures with different $\mathrm{H}_{2} \mathrm{O}$ fractions at a concentration of $0.1 \mathrm{~g} / \mathrm{L}$; (c) Plot of PL intensity of TPE-PE $82-b$-P $t$ BA $A_{x}$ at $483 \mathrm{~nm}$ versus $\mathrm{H}_{2} \mathrm{O}$ fraction in $\mathrm{THF} / \mathrm{H}_{2} \mathrm{O}$ mixture; (d) Plot of $\mathrm{I} / \mathrm{I}_{0}$ and transmittance of TPE-PE $82-b-\mathrm{P} t \mathrm{BA}_{29}$ versus $\mathrm{H}_{2} \mathrm{O}$ fraction in the $\mathrm{THF} / \mathrm{H}_{2} \mathrm{O}$ mixture; I is $\mathrm{PL}$ intensity in $\mathrm{THF} / \mathrm{H}_{2} \mathrm{O}$ mixtures with different $\mathrm{H}_{2} \mathrm{O}$ fractions, $\mathrm{I}_{0}$ is $\mathrm{PL}$ intensity in pure THF solution.

Self-Assembly of Block Copolymers. PE-based block copolymers in selective solvents for the one block self-assemble to form micellar structures. For example, in the case of TPE-PE- $b$-P $t$ BA, DMF is a selective solvent for PtBA and therefore the DMF-phobic TPE-PE block will form the core while $\mathrm{P} t \mathrm{BA}$ the corona. As a consequence, the aggregated polyethylene chains will restrict the intramolecular rotation of TPE and thus enhance the FL intensity. To investigate the relationship between the FL intensity and self-assembled behavior, a series of TPE-PE $82-b-\mathrm{P} \mathrm{BA} \mathrm{x}_{\mathrm{x}}$ 
DMF solutions with different concentration were prepared and the AIE behaviors were checked (Figure S8).
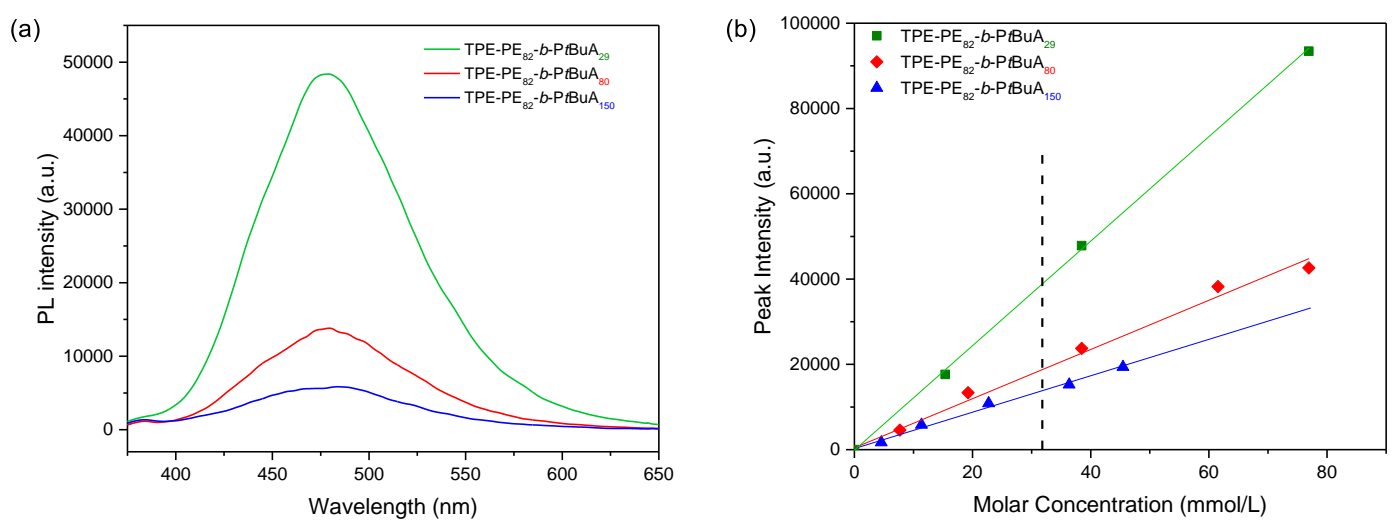

Figure 6. (a) PL spectra of TPE-PE $\mathrm{P}_{22}-b-\mathrm{P}_{\mathrm{B}} \mathrm{BA}_{\mathrm{x}}$ in DMF solutions at a concentration of $0.25 \mathrm{~g} / \mathrm{L}$; (b) Plot of peak intensity of TPE-PE $82-b-\mathrm{P}_{t} \mathrm{BA}_{\mathrm{x}}$ solutions at $483 \mathrm{~nm}$ as a function of the TPE concentration in $\mathrm{mmol} / \mathrm{L}$ from Figure $\mathrm{S} 8$.

All solutions of TPE-PE $82-b-\mathrm{P} t \mathrm{BA}_{\mathrm{x}}$ copolymers shown strong emission intensities. Comparing the emission intensities of DMF solutions (Figure 6a) to those in $\mathrm{THF} / \mathrm{H}_{2} \mathrm{O}$ mixtures (Figure 5d), it is obvious that as in the case of THF/ $\mathrm{H}_{2} \mathrm{O}$, the higher TPE content of the block copolymer (lower molecular weight) the higher intensity. As shown in figure $6 \mathrm{~b}$, the intensity is plotted against the concentration in $\mathrm{mmol} / \mathrm{L}$, concentration in $\mathrm{mmol} / \mathrm{L}$ was used in order to normalize the TPE concentration in each case. The solution of TPE-PE $82-b-\mathrm{P} \mathrm{BA}_{29}$ still has the highest emission intensity comparing to other two block copolymers, although the concentration of TPE group was the same. 

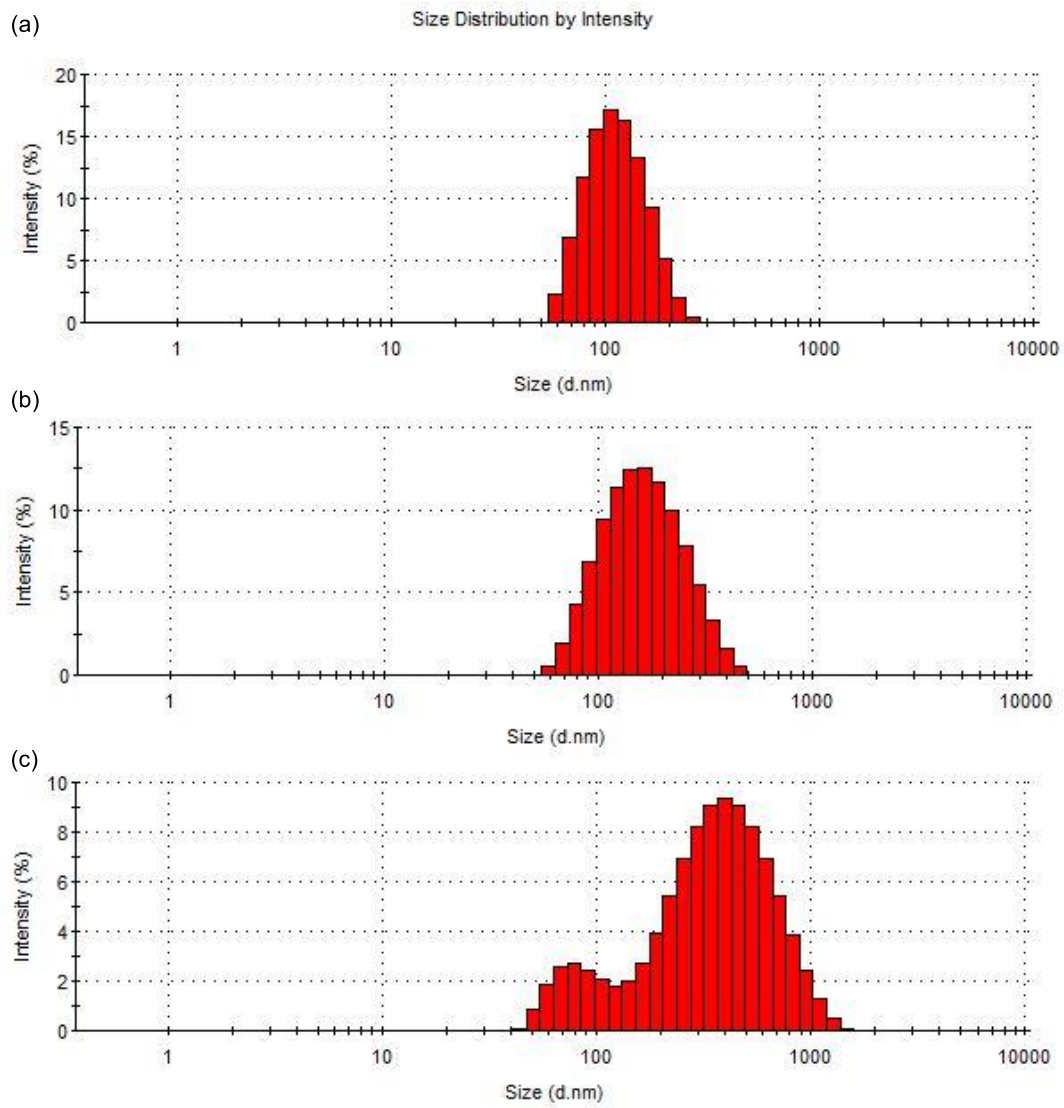

Figure 7. Size distribution of TPE-PE $82-b-\mathrm{P}_{t} \mathrm{BA}_{\mathrm{x}}$ in DMF (a) TPE-PE $82-b-\mathrm{P}_{t} \mathrm{BA}_{150}$; (b) TPE-PE $82-$ $b$-P $t \mathrm{BA}_{80}$; (c) TPE-PE $82-b-\mathrm{P} t \mathrm{BA}_{29}$.

The size distribution of the formed micelles in DMF were measured by dynamic light scattering (DLS) at room temperature (Figure 7). It is obvious that the lower the molecular weight of the PtBA block the higher the size of the micelles, due to the higher PE content of block copolymer. This is in agreement with the PL intensity results since the lower molecular weight copolymer has the higher aggregation (TPE-PE: fixed molecular weight).

Critical Micelle Concentration (CMC) of TPE-PE-b-PtBA in DMF. CMC is defined as the concentration below which only single chains are present and above the single chains can selfassemble into micelles. At concentration above $\mathrm{CMC}$, the aggregation of TPE-PE chain in the core 
region should exert AIE-operative emission, while at a concentration below $\mathrm{CMC}$, the polymer chain are isolated in the dilute solution and there should be no emission expected in this case.

(a)

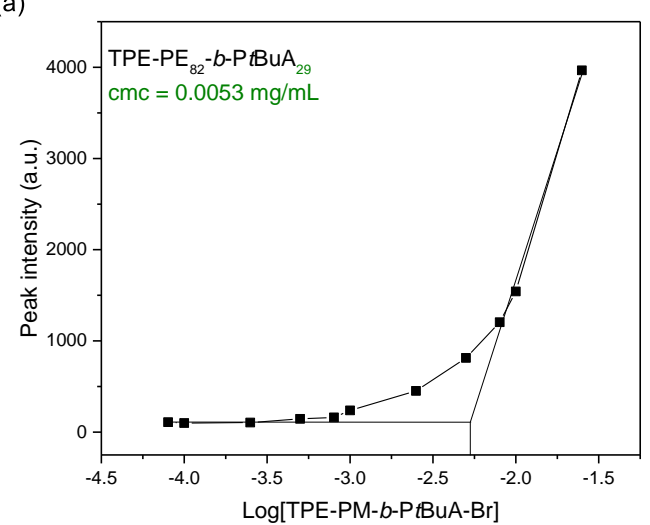

(c)

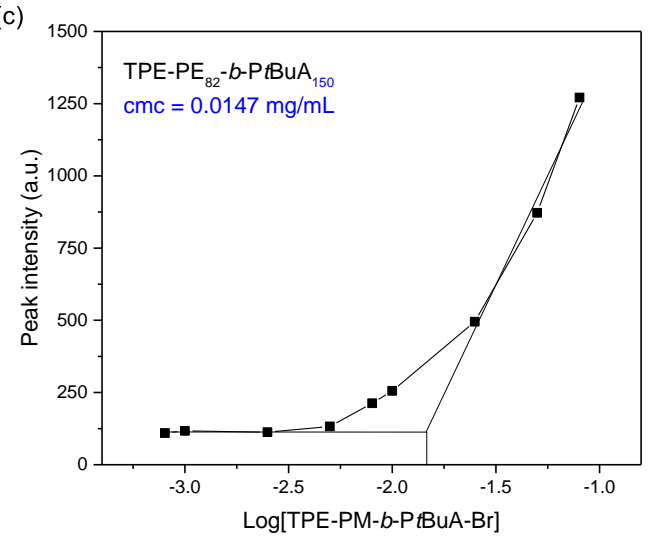

(b)

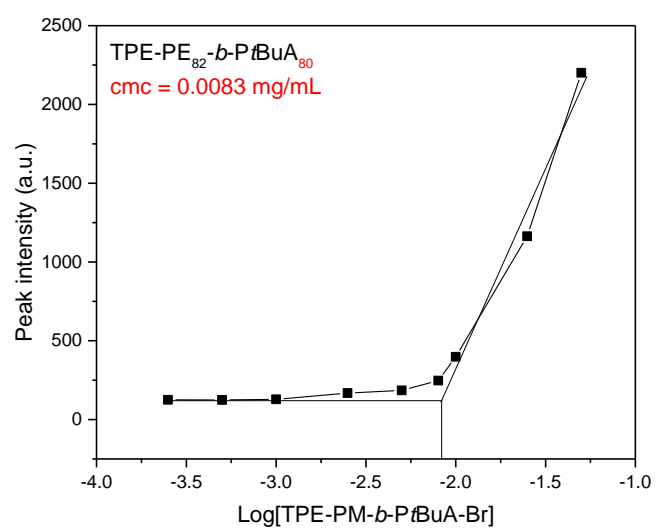

(d)

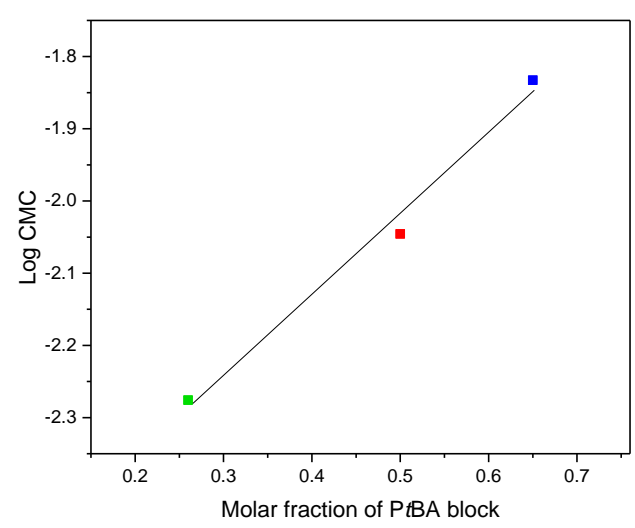

Figure 8. (a-c) Plot of emission intensity at $483 \mathrm{~nm}$ versus the logarithm of the concentration of TPE-PE $82-b-\mathrm{PtBA}_{x}$; (d) Plot of Log CMC versus the molar fraction of P $t \mathrm{BA}$ block.

The relationship of fluorescence intensity toward the concentration of the TPE-PE $82-b-\mathrm{PtBA}_{\mathrm{x}}$ solution in DMF was used to locate the CMC. A series of TPE-PE $82-b-\mathrm{PtBA}_{\mathrm{x}}$ solutions in DMF were prepared and all the AIE behaviors were investigated. The PL spectra are shown in Figure S6. The aggregate emission intensity at $483 \mathrm{~nm}$ was plotted against the logarithm of the concentration of the DMF solutions (Figure 8, a-c), the emission intensities remain very low when the concentration is below $\mathrm{CMC}$ and increase sharply above the $\mathrm{CMC}$ in all block polymers. The 
CMC values of the block copolymer solutions are in the range of $(0.5-1.5) \times 10^{-2} \mathrm{mg} / \mathrm{mL}$, indicating an obvious effect of the PtBA lengths on the CMC values. With the highest PtBA content, TPE$\mathrm{PE}_{82}-b-\mathrm{PtBA}_{150}$ has the highest $\mathrm{CMC}$ value $\left(1.47 \times 10^{-2} \mathrm{mg} / \mathrm{mL}\right)$ compared to the other two block polymers. This result is reasonable because the longer $\mathrm{P} t \mathrm{BA}$ chain will prevent $\mathrm{PE}$ block to aggregate, so the one who has longer PtBA chain will form micelle later than others. As depicted

in Figure 8d, a linear relationship between logarithm CMC and molar fraction of $\mathrm{P} t \mathrm{BA}$ chain in the block copolymer $\left(\mathrm{DP}_{\mathrm{P}_{t B \mathrm{~B}}} /\left(\mathrm{DP}_{\mathrm{PE}_{\mathrm{E}}}+\mathrm{DP}_{\mathrm{P} t \mathrm{BA}}\right)\right)$ are observed, and the $\mathrm{CMC}$ value increases as the molar fraction of $\mathrm{P} t \mathrm{BA}$ chain increases at constant $\mathrm{PE}$ length.

\section{CONCLUSION}

In summary, a series of TPE-functionalized PE-based homo/copolymers were synthesized by using polyhomologation. Tris(3-(4-(1,2,2-triphenylvinyl)phenoxy)propyl)borane was used as initiator for the polyhomologation of dimethylsulfoxonium methylide to give TPE-terminated linear polyethylene. Combining this method with ROP or ATRP, more TPE-active PE-based block copolymers were synthesized. All synthesized polymers showed AIE-behavior either in solution or in bulk. The DMF solution of block copolymer TPE-PE- $b$-P $t$ BA can undergo self-assembly to give micelle solutions with strong emission. The TPE-PE-core in the micelle restricts the intramolecular rotation of TPE and thus enhances FL emission intensity. The block copolymer with lower PtBA block composition forms micelle with the larger size, which results in higher PL emission intensity. CMC value of TPE-PE- $b$-PtBA was determined by using the response of the AIE behavior toward the concentration of the block polymer solutions. This research opens new horizons toward potential application of PE-based polymer in AIE materials. 


\section{ASSOCIATED CONTENT}

Supporting Information. Additional figures are presented in the supporting inforamtion. This material is available free of charge via the Internet at http://pubs.acs.org.

\section{AUTHOR INFORMATION}

\section{Corresponding Author}

* (N.H.) Telephone: +966-(0)12-8080789. E-mail: nikolaos.hadjichristidis@kaust.edu.sa.

\section{ORCID}

Yu Jiang: 0000-0002-8781-6381

Nikos Hadjichristidis: 0000-0003-1442-1714

\section{Notes}

The authors declare no competing financial interest.

\section{ACKNOWLEDGMENT}

The authors like to thank Dr. Panagiotis Bilalis for his help on the investigation of self-assembly. The research reported in this publication was supported by King Abdullah University of Science and Technology (KAUST). 


\section{REFERENCES}

1. Bredol, M.; Kynast, U.; Ronda, C., Designing luminescent materials. Adv. Mater. 1991, 3, 361-367.

2. Schmidt, A.; Anderson, M.; Armstrong, N., Electronic states of vapor deposited electron and hole transport agents and luminescent materials for light-emitting diodes. J. Appl. Phys. 1995, 78, 5619-5625.

3. Jüstel, T.; Nikol, H.; Ronda, C., New developments in the field of luminescent materials for lighting and displays. Angew. Chem., Int. Ed. 1998, 37, 3084-3103.

4. Bünzli, J.-C. G., Lanthanide luminescence for biomedical analyses and imaging. Chem. Rev. 2010, 110, 2729-2755.

5. $\quad$ Förster, T.; Kasper, K., Ein konzentrationsumschlag der fluoreszenz des pyrens. Z. Phys. Chem. (Muenchen, Ger.) 1955, 59, 976-980.

6. Luo, J.; Xie, Z.; Lam, J. W.; Cheng, L.; Chen, H.; Qiu, C.; Kwok, H. S.; Zhan, X.; Liu, Y.; Zhu, D., Aggregation-induced emission of 1-methyl-1, 2, 3, 4, 5-pentaphenylsilole. Chem. Commun. 2001, 1740-1741.

7. Hong, Y.; Lam, J. W.; Tang, B. Z., Aggregation-induced emission. Chem. Soc. Rev. 2011, 40, 5361-5388.

8. Mei, J.; Hong, Y.; Lam, J. W.; Qin, A.; Tang, Y.; Tang, B. Z., Aggregation-induced emission: the whole is more brilliant than the parts. Adv. Mater. 2014, 26, 5429-5479.

9. Mei, J.; Leung, N. L.; Kwok, R. T.; Lam, J. W.; Tang, B. Z., Aggregation-induced emission: together we shine, united we soar! Chem. Rev. 2015, 115, 11718-11940.

10. Kwok, R. T.; Leung, C. W.; Lam, J. W.; Tang, B. Z., Biosensing by luminogens with aggregation-induced emission characteristics. Chem. Soc. Rev. 2015, 44, 4228-4238.

11. Feng, H.-T.; Yuan, Y.-X.; Xiong, J.-B.; Zheng, Y.-S.; Tang, B. Z., Macrocycles and cages based on tetraphenylethylene with aggregation-induced emission effect. Chem. Soc. Rev. 2018, 47, $7452-7476$.

12. Hu, R.; Kang, Y.; Tang, B. Z., Recent advances in AIE polymers. Polymer Journal 2016, $48,359$.

13. Hu, R.; Leung, N. L.; Tang, B. Z., AIE macromolecules: syntheses, structures and functionalities. Chem. Soc. Rev. 2014, 43, 4494-4562.

14. Qin, A.; Lam, J. W.; Tang, B. Z., Luminogenic polymers with aggregation-induced emission characteristics. Prog. Polym. Sci. 2012, 37, 182-209.

15. Schatz, C.; Louguet, S.; Le Meins, J. F.; Lecommandoux, S., Polysaccharide-blockpolypeptide copolymer vesicles: towards synthetic viral capsids. Angew. Chem., Int. Ed. 2009, 48, 2572-2575.

16. Wang, Y.; Xu, H.; Zhang, X., Tuning the amphiphilicity of building blocks: controlled selfassembly and disassembly for functional supramolecular materials. Adv. Mater. 2009, 21, 28492864.

17. Meng, F.; Zhong, Z.; Feijen, J., Stimuli-responsive polymersomes for programmed drug delivery. Biomacromolecules 2009, 10, 197-209.

18. Vriezema, D. M.; Comellas Aragonès, M.; Elemans, J. A.; Cornelissen, J. J.; Rowan, A. E.; Nolte, R. J., Self-assembled nanoreactors. Chem. Rev. 2005, 105, 1445-1490.

19. Zhang, X.; Zhang, X.; Tao, L.; Chi, Z.; Xu, J.; Wei, Y., Aggregation induced emissionbased fluorescent nanoparticles: fabrication methodologies and biomedical applications. J. Mater. Chem. B 2014, 2, 4398-4414. 
20. Wang, J.; Wang, S.; Zhou, Y.; Wang, X.; He, Y., Fast photoinduced large deformation of colloidal spheres from a novel 4-arm azobenzene compound. ACS Appl. Mater. Interfaces 2015, 7, 16889-16895.

21. Yan, L.; Zhang, Y.; Xu, B.; Tian, W., Fluorescent nanoparticles based on AIE fluorogens for bioimaging. Nanoscale 2016, 8, 2471-2487.

22. Zhao, Y.; Wu, Y.; Chen, S.; Deng, H.; Zhu, X., Building single-color AIE-active reversible micelles to interpret temperature and $\mathrm{pH}$ stimuli in both solutions and cells. Macromolecules 2018, 51, 5234-5244.

23. Wang, H.; Wu, C.; Xia, G.; Ma, Z.; Mo, G.; Song, R., Semi-crystalline polymethylene-bpoly (acrylic acid) diblock copolymers: aggregation behavior, confined crystallization and controlled growth of semicrystalline micelles from dilute DMF solution. Soft matter 2015, 11, $1778-1787$.

24. Schöbel, J.; Karg, M.; Rosenbach, D.; Krauss, G.; Greiner, A.; Schmalz, H., Patchy Wormlike micelles with tailored functionality by crystallization-driven self-assembly: A versatile platform for mesostructured hybrid materials. Macromolecules 2016, 49, 2761-2771.

25. Fan, B.; Liu, L.; Li, J.-H.; Ke, X.-X.; Xu, J.-T.; Du, B.-Y.; Fan, Z.-Q., Crystallizationdriven one-dimensional self-assembly of polyethylene-b-poly (tert-butylacrylate) diblock copolymers in DMF: effects of crystallization temperature and the corona-forming block. Soft Matter 2016, 12, 67-76.

26. Fan, B.; Xue, J.-Q.; Guo, X.-S.; Cao, X.-H.; Wang, R.-Y.; Xu, J.-T.; Du, B.-Y.; Fan, Z.-Q., Regulated fragmentation of crystalline micelles of block copolymer via monoamine-induced corona swelling. Macromolecules 2018, 51, 7637-7648.

27. Gilroy, J. B.; Gädt, T.; Whittell, G. R.; Chabanne, L.; Mitchels, J. M.; Richardson, R. M.; Winnik, M. A.; Manners, I., Monodisperse cylindrical micelles by crystallization-driven living self-assembly. Nat. Chem. 2010, 2, 566.

28. Hudson, Z. M.; Boott, C. E.; Robinson, M. E.; Rupar, P. A.; Winnik, M. A.; Manners, I., Tailored hierarchical micelle architectures using living crystallization-driven self-assembly in two dimensions. Nat. Chem. 2014, 6, 893.

29. He, W.-N.; Xu, J.-T., Crystallization assisted self-assembly of semicrystalline block copolymers. Prog. Polym. Sci. 2012, 37, 1350-1400.

30. Yang, J.; Liu, L.; Xu, J., Crystalline micelles of block copolymers. Prog. Chem. 2014, 26, 1811-1820.

31. Luo, J.; Shea, K. J., Polyhomologation. A living C1 polymerization. Acc. Chem. Res. 2010, 43, 1420-1433.

32. Shea, K.; Walker, J.; Zhu, H.; Paz, M.; Greaves, J., Polyhomologation. A living polymethylene synthesis. J. Am. Chem. Soc. 1997, 119, 9049-9050.

33. Shea, K. J., Polyhomologation: The living polymerization of ylides. Chem. - Eur. J. 2000, 6, 1113-1119.

34. Wang, D.; Zhang, Z.; Hadjichristidis, N., C1 polymerization: a unique tool towards polyethylene-based complex macromolecular architectures. Polym. Chem. 2017, 8, 4062-4073.

35. Li, Q. Z.; Zhang, G. Y.; Chen, J. Z.; Zhao, Q. L.; Lu, H. C.; Huang, J.; Wei, L. H.; D'agosto, F.; Boisson, C.; Ma, Z., Well - defined polyolefin/poly ( $\varepsilon$-caprolactone) diblock copolymers: New synthetic strategy and application. J. Polym. Sci., Part A: Polym. Chem. 2011, 49, 511-517.

36. Lu, H. C.; Xue, Y.; Zhao, Q. L.; Huang, J.; Xu, S. G.; Cao, S. K.; Ma, Z., Well - defined amphiphilic polymethylene- $b$-poly (acrylic acid) diblock copolymers: New synthetic strategy and their self-assembly. J. Polym. Sci., Part A: Polym. Chem. 2012, 50, 3641-3647. 
37. Xue, Y.; Lu, H.-C.; Zhao, Q.-L.; Huang, J.; Xu, S.-G.; Cao, S.-K.; Ma, Z., Polymethylene$b$-poly (styrene-co-2, 3, 4, 5, 6-pentafluoro styrene) copolymers: synthesis and fabrication of their porous films. Polym. Chem. 2013, 4, 307-312.

38. Li, J.; Zhao, Q.-L.; Chen, J.-Z.; Li, L.; Huang, J.; Ma, Z.; Zhong, Y.-W., Highly ordered microporous films containing a polyolefin segment fabricated by the breath-figure method using well-defined polymethylene- $b$-polystyrene copolymers. Polym. Chem. 2010, 1, 164-167.

39. Zhang, H.; Gnanou, Y.; Hadjichristidis, N., Well-defined polyethylene molecular brushes by polyhomologation and ring opening metathesis polymerization. Polym. Chem. 2014, 5, 64316434.

40. Zapsas, G.; Ntetsikas, K.; Kim, J.; Bilalis, P.; Gnanou, Y.; Hadjichristidis, N., Boron "stitching" reaction: a powerful tool for the synthesis of polyethylene-based star architectures. Polym. Chem. 2018, 9, 1061-1065.

41. Shea, K. J.; Busch, B. B.; Paz, M. M., Polyhomologation: Synthesis of novel polymethylene architectures by a living polymerization of dimethylsulfoxonium methylide. Angew. Chem., Int. Ed. 1998, 37, 1391-1393.

42. Zhang, Z.; Zhang, H.; Gnanou, Y.; Hadjichristidis, N., Polyhomologation based on in situ generated boron-thexyl-silaboracyclic initiating sites: a novel strategy towards the synthesis of polyethylene-based complex architectures. Chem. Commun. 2015, 51, 9936-9938.

43. Zhang, Z.; Gnanou, Y.; Hadjichristidis, N., Well-defined 4-arm stars with hydroxyterminated polyethylene, polyethylene- $b$-polycaprolactone and polyethylene- $b$-(polymethyl methacrylate) $)_{2}$ arms. Polym. Chem. 2016, 7, 5507-5511.

44. Zhang, Z.; Altaher, M.; Zhang, H.; Wang, D.; Hadjichristidis, N., Synthesis of well-defined polyethylene-based 3-miktoarm star copolymers and terpolymers. Macromolecules 2016, 49, 2630-2638.

45. Zhang, H.; Banerjee, S.; Faust, R.; Hadjichristidis, N., Living cationic polymerization and polyhomologation: an ideal combination to synthesize functionalized polyethylenepolyisobutylene block copolymers. Polym. Chem. 2016, 7, 1217-1220.

46. Wang, D.; Hadjichristidis, N., Allyl borates: a novel class of polyhomologation initiators. Chem. Commun. 2017, 53, 1196-1199.

47. Xue, Y.; Zhang, S.-S.; Cui, K.; Huang, J.; Zhao, Q.-L.; Lan, P.; Cao, S.-K.; Ma, Z., New polymethylene-based $\mathrm{AB}_{2}$ star copolymers synthesized via a combination of polyhomologation of ylides and atom transfer radical polymerization. RSC Adv. 2015, 5, 7090-7097.

48. Wang, H.; Xu, F.; Cui, K.; Zhang, H.; Huang, J.; Zhao, Q.; Jiang, T.; Ma, Z., Synthesis of polymethylene- $b$-poly(vinyl acetate) block copolymer via visible light induced radical polymerization and its application. $R S C A d v$. 2017, 7, 42484-42490.

49. He, Q.; Ren, J.; Ren, J.; Pang, K.; Ma, Z.; Zhu, X.; Song, R., Polymethylene- $b$-poly (acrylic acid) diblock copolymers: Aggregation and crystallization in the presence of $\mathrm{CaCl}_{2}$. European Polymer Journal 2017, 95, 174-185.

50. Jiang, Y.; Zhang, Z.; Wang, D.; Hadjichristidis, N., An Efficient and general strategy toward the synthesis of polyethylene-based cyclic polymers. Macromolecules 2018, 51, 31933202.

51. Corey, E.; Chaykovsky, M., Dimethyloxosulfonium methylide $\left(\left(\mathrm{CH}_{3}\right)_{2} \mathrm{SOCH}_{2}\right)$ and dimethylsulfonium methylide $\left(\left(\mathrm{CH}_{3}\right)_{2} \mathrm{SCH}_{2}\right)$. Formation and application to organic synthesis. $J$. Am. Chem. Soc. 1965, 87, 1353-1364. 
52. Zhang, H.; Alkayal, N.; Gnanou, Y.; Hadjichristidis, N., Anionic polymerization and polyhomologation: an ideal combination to synthesize polyethylene-based block copolymers. Chem. Commun. 2013, 49, 8952-8954. 
For Table of Contents Use Only

\section{Tetraphenylethene-Functionalized Polyethylene-based Polymers with Aggregation-Induced Emission}

Yu Jiang, Nikos Hadjichristidis*

Table of Contents Graphic

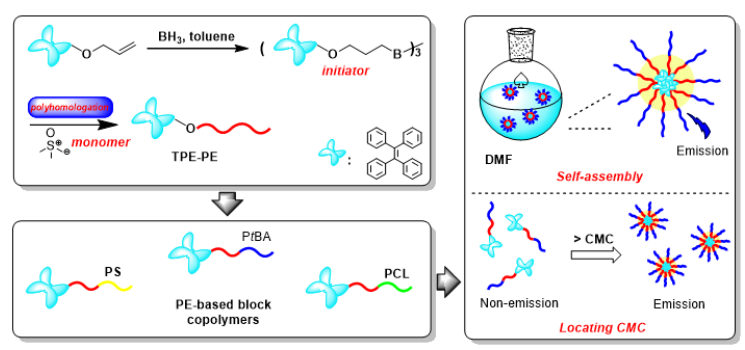

